\title{
IMPLEMENTASI RASPBERRY PI UNTUK APLIKASI SIGNATE BOARD JADWAL KULIAH BERBASIS WEB DENGAN SISTEM OPERASI LINUX
}

\author{
Agus Triyono \\ Jurusan Teknologi Informasi Politeknik Negeri Samarinda \\ Jl.Ciptomangunkusumo Kampus Gn.Lipan, Samarinda \\ E-Mail: triyono@polnes.ac.id
}

\begin{abstract}
ABSTRAK
Raspberry adalah komputer dengan ukuran fisik yang minimalis dengan kemampuan seperti komputer biasa. Hal ini dapat dimanfaatkan untuk berbagai macam keperluan salah satunya adalah sebagai pemroses penampil jadwal kuliah dengan menggunakan TV layar lebar sebagai media penampil. Sistem terdiri dari dari Raspbery Pi sebagai web hosting, databse server sebagai storage, sebagai router untuk berkomunikasi dengan jaringan TCP/IP dan secure shell servaer sebagai akses untuk proses administrasi atau konfigurasi. Dengan ukuran RAM dan bentuk yang minimal Raspberry Pi dapar menopang operasi-operasi tersebut dengan maksimal. Dengan demikian Raspberry Pi akan diuji kemampuannya jika difungsikan sebagai web server, database server dan SSH server dengan kegunaan sistem informasi jadwal kuliah berbasih web.
\end{abstract}

Kata Kunci: Raspberry Pi, Signate Board, Crontab, Linux, Debian 7, Wheezy, Jadwal Kuliah

\section{PENDAhuluan}

Signate adalah tanda atau symbol yang ditujukan untuk memberikan pesan kepada group secara spesifik, biasanya ditujukan untuk keperluan marketing atau pesan-pesan yang lain(Russell \& Gregory Stone, 2002, Dictionary, 2003). Sebuah signate juga dapat diartikan adalah tanda secara sekumpulan tanda atau pesan(Meis \& Kashima, 2017).

Papan reklame digital (yang secara resmi dinamakan " Changeable Electronic Variable Message Signs" atau "CEVMS") menandai kemajuan besar dalam iklan luar ruangan dan signate karena memungkinkan pesan atau gambar yang dapat diubah, dan secara drastis mengurangi biaya perubahan pesan / gambar (dalam beberapa kasus bahkan mengaktifkan perubahan jarak jauh dari pesan / gambar), dan mengizinkan beberapa pesan / gambar diulang-ulang sesuai dengan jadwal(Ford \& Cartwright, 2018).

Teknologi saat ini begitu maju sehingga TV LED berskala rumah tangga dapat digunakan sebagai signate board ini akibat TV LED dapat dijadikan layar monitor komputer biasa sehingga Sistem Informasi jadwal kuliah dapat ditampilkan melalu web dengan menggunakan TV LED berlayar lebar sebagai media penampil(Park dkk., 2018).

Sistem Informasi Penjadwalan mata kuliah memberikan informasi terkait jadwal mata kuliah yang memberikan informasi mata kuliah yang sedang berlangsung berikut informasi ruangan, dosen pengampu dan status kehadiran, tepat waktu atau dibatalkan dengan tujuan mahasiswa tidak perlu lagi mencari kelas atau kehadiran pengampu mata kuliah tersebut.

\section{RUANG LINGKUP}

Penulisan ini mempunyai ruang lingkup pemrograman dengan menggunakan PHP dan konfigurasi pada Raspberry Pi yang terkait dengan web server, secure shell server ( $\mathrm{SSH}$ ) dan database server yang akan di implementasikan sebagai sistem informasi jadwal kuliah, serta mengamati kehandalan perangkat di lihat dari sisi endurance dengan sistem yang minimal menggunakan Linux sebagai operating system.

\section{BAHAN DAN METODE}

Perangkat terdiri dari modul yang sudah jadi dengan ukuran fisik dan harga seminal mungkin namun didapat performa yang baik sekali baik dari operating system maupun aplikasi yang terpasang.

Aplikasi sudah tersedia pada repository Linux melalui internet sehingga dipilih yang hanya diperlukan saja untuk menghemat RAM yang tersedia dan menghemat beban proses pada saat terjadi query database yang besar.

Interval Timer yang digunakan untuk meng-update database adalah menggunakan crontab dan untuk mengupdate informasi di dalam web menggunakan fasilitas refresh secara otomatis pada fitur web

\subsection{Raspberry Pi}

Raspberry Pi adalah single-board computer yang dikembangkan di United Kingdom oleh yayasan Raspberry Pi untuk memperkenalkan dalam dunia pendidikan tentang dasar-dasar teknik komputer (computer science) di negara-negara berkembang(O’Leary dkk., 2018). 
Jantung dari RPi (Raspberry Pi) adalah sirkuit terintegrasi menggabungkan prosesor ARM $700 \mathrm{MHz}$ (CPU), Broadcom Prosesor grafis VideoCore (GPU), dan 256/512 MB dari RAM pada satu chip. Dengan kartu SD slot untuk penyimpanan dan unit I/O seperti USB, Ethernet, audio, Video RCA, dan HDMI. Daya disediakan melalui micro-USB konektor. Terdapat dua varian, yaitu A dan B, dengan model B menawarkan fitur-fitur yang tidak dimiliki model A: ia memiliki 512 MB RAM (bukan 256 MB) dan Ethernet onboard(O'Leary dkk., 2018).

Dalam hal perangkat lunak sistem, Yayasan Raspberry merekomendasikan menggunakan Raspbian sebagai sistem operasi (OS). Rasp-bian adalah port dari Debian distribusi Linux yang terkenal dioptimalkan untuk set instruksi ARMv6, mis. menyediakan lebih baik kinerja untuk operasi aritmatika floating point. Saat ini, Raspbian hadir dengan sekitar 35.000 paket prebuilt, menyederhanakan proses menginstal perangkat lunak pada RPI. Sistem operasi (atau akan segera) lainnya tersedia untuk RPi juga, ini termasuk Android, Arch Linux ARM, Firebox OS, Google Chromium, Fedora, Plan 9 dari Bell lab, RISC OS, dan UNIX(Abrahamsson dkk., 2013).

\subsection{Debian 7 (Wheezy)}

Debian 7 (Wheezy) di release 4 May 2013 yang berisi lebih dari 35000 paket. Diperuntukkan mendukung UEFI, Debian di porting ke arsitektur armhf dan IBM ESA/390(s390x)(Abrahamsson dkk., 2013).

Dipilihnya Debian 7 (Wheezy) adalah mampu menjalankan paket-paket seperti Apache untuk web server, MySQL sebagai Database server dan juga apache sebagai syarat untuk dapat menjalankan web server dan databasenya dengan hanya memerlukan RAM sebesar 512 MB. Juga mempunyai fasilitas remote access yaitu dengan menggunakan aplikasi SSH. Dalam hal ini Raspberry Pi mampu berperan sebagai SSH Server yang aman untuk diakses.

\subsection{Crontab}

Cron adalah utility software yang berbasis waktu untuk scheduler di Linux Operating sistem(Saito dkk., 2015). Dalam bekerja memaintain perangkat lunak cron dapat digunakan untuk mengerjakan pekerjaan yang terjadwal. Cron dapat diekseskusi melalui commands atau shell scrips. Dalam membuat penjadwalan melalui cron melalui sebuah file tertentu dibawah direktori /etc(Lakkaraju, 2010). Didalam file tersebut berisi barisbaris yang berisi pendajadwalan dengan format pada gambar 1.

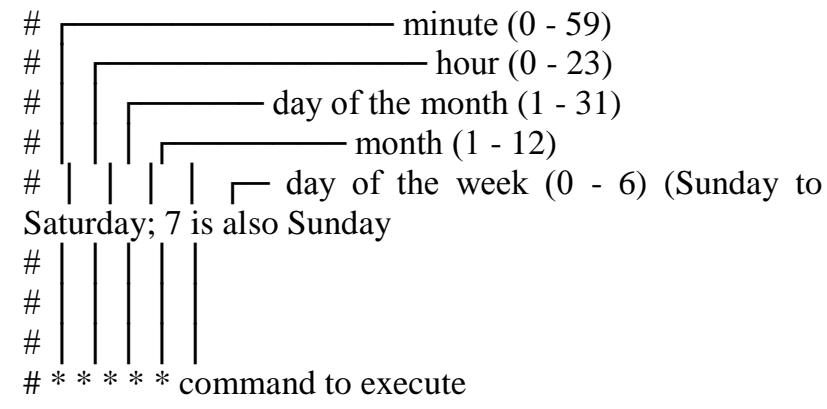

Gambar 1. Isi Dari File Crontab

Perintah yang terdapat pada setiap baris terdiri dari 5 field yang diikuti dengan shell command untuk dieksekusi(Ritchie \& Thompson, 1978). Secara normal untuk meng-eksekusi job yang sudah dijadwalkan hanya ada satu pengecualian yaitu: jika day of month (field 3) dan day of week (field 5) tidak memenuhi (bukan “*”), maka satu diantara keduanya harus cocok dengan hari saat ini.

\subsection{SSH Server}

Untuk dapat meng-akses server untuk kepentingan administrasi dan pemrograman diperlukan aplikasi untuk remote akses, yaitu akses yang dapat digunakan secara remote atau jarak jauh. Untuk itu diperlukan SSH Server untuk di server dan SSH Client untuk Client.

Secure Shell (SSH) adalah protokol jaringan terekripsi untuk mengoperasikan layanan jaringan secara aman melalui jaringan yang tidak aman(Ylonen \& Lonvick, 2005).

Terdapat dua protocol yang ada di SSH yaitu SSH-1 dan SSH-2. Port TCP standar untuk SSH adalah 22(Ylonen \& Lonvick, 2005). SSH umumnya digunakan untuk mengakses sistem operasi mirip Unix, tetapi juga dapat digunakan pada Windows. Windows 10 menggunakan OpenSSH sebagai client SSH default-nya.

\subsection{MySQL}

Relational Data Base Management System (RDBMS) yang paling banyak digunakan di dunia(Konopásek dkk.) dan RDBMS adalah Open Source.

Ada dua acara untuk dapat mengakses database ini yaitu melalui shell command dan web. Menggunakan web lebih praktis karena pengguna tidak perlu mengetikkan perintah-perintah terutama pada saat melakukan Data Query dan sangat user friendly. Untuk dapat akses ini administrator harus men-instal dan mengkonfigurasi Apache dan berikut PHP-server(Meloni, 2012). 


\subsection{Apache}

Apache adalah perangkat lunak untuk web server yang bersifat cross-platform gratis dan open-source, yang dirilis di bawah ketentuan Apache License 2.0(Kraus dkk., 2018). Apache dikembangkan dan dikelola oleh komunitas pengembang terbuka di bawah naungan Apache Software Foundation(Hussain dkk., 2018).

Secara default apache meletakkan design ataupun aplikasi web ke folder /var/www untuk Linux Debian (Wheezy) dan file berupa index.html sebagai file default. File ini bisa diganti isinya sesuai dengan kebutuhan.

\section{PEMBAHASAN}

Raspberry Pi yang berfungsi sebagai pusat pengolahan data sistem informasi jadwal kuliah diakses menggunakan protokol TCP/IP baik wireline maupun wireless untuk kegiatan konfigurasi dan sistem administrasi yang kesemuanya berbasis web. Karena posisi display jauh dari jangkauan operator sehingga Raspberry diletakkan dekat dengan display yang mengakibatkan kegiatan dilakukan secara remote.

\subsection{Blok Diagram Signate Board}

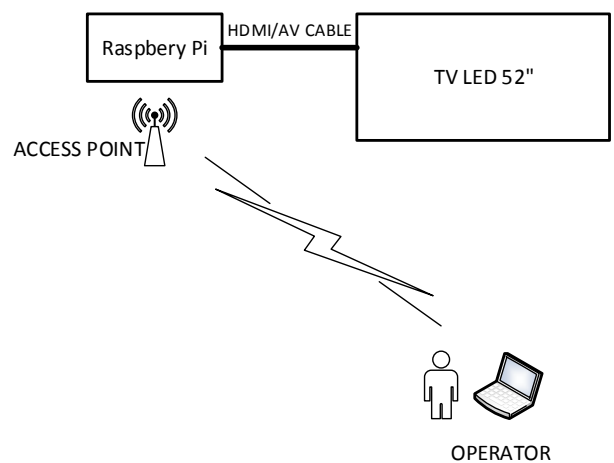

\section{Gambar 2. Blok Diagram Signate Board Sistem Informasi Penjadwalan Mata Kuliah}

Hubungan antara Raspberry Pi dan TV LED 52" dapat berupa kabel HDMI atau kabel RCA Video (lihat gambar 2). Rasberry Pi juga dihubungkan dengan Access Point yang terhubung melalui WiFi dengan Operator dengan IP address tertentu. Operator harus dapat mengakses Access Point tersebut dan

Operator memasukkan data berupa jadwal mata kuliah satu semester yang berisi Mata Kuliah, Semester, Jam, Status, dan Ruang menggunakan aplikasi excel dalam bentuk CSV. Oprator kemudian meng-upload data tersebut melalui fitur upload pada aplikasi Sistem Informasi Penjadwalan. Data yang dimasukkan oleh operator sudah selesai diupload dan menunggu sistem untuk menampilkan ke penampil TV LED sesuai dengan waktu sistem.
Apabila ada perubahan jadwal yang mendadal dan bersifat temporer maka operator akan memperbaharui data yang akan dirubah. Data yang berubah secara temporer tersebut tidak akan muncul pada jadwal perkuliahan minggu depan.

\subsection{BLOK DIAGRAM DASAR SISTEM APLIKASI DAN TIMER}

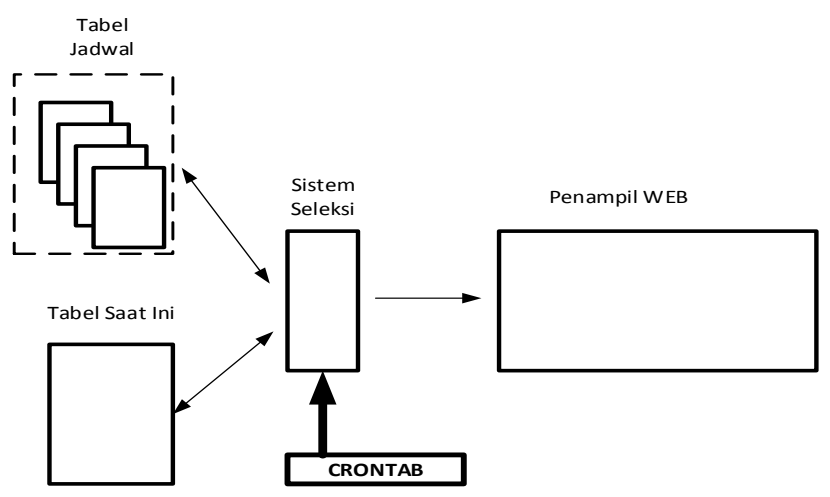

Gambar 3. Blok Diagram Dasar Sistem Aplikasi

Pada Gambar 3. Terdapat 3 bagian penting yaitu table jadwal, table saat ini, sistem seleksi dan Penampil web. Seluruh informasi jadwal per satu semester akan dimasukkan oleh operator kedalam table jadwal melalaui aplikasi. Sistem seleksi kemudian memilih berdasarkan tanggal dan jam yang akan ditampilkan pada penampil web dan dimasukkan kedalam table saat ini. Pergantian jam kuliah dilakukan oleh script yang terdapat pada sistem seleksi yang sesuai dengan jadwal yang telah ditentukan. Untuk menyesuaikan antara jam yang telah ditentukan didalam script dan jadwal yang ada didalam table jadwal maka diperlukan timer berupa crontab. Crontab ini berfungsi sebagai timer yang akan mengeksekusi sistem seleksi setiap detiknya. Sehingga pencocokan antara jadwal yang ada didalam sistem seleksi dan table jadwal sessi (lihat gambar 4).

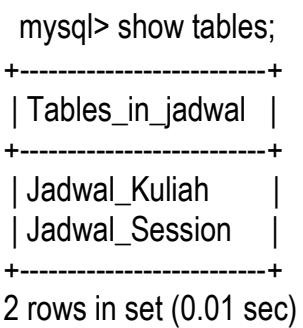

Gambar 4. Tabel dari Database Jadwal 
Terdapat cukup dua table yang diperlukan untuk sistem informasi ini yaitu Jadwal_Kuliah dan

mysq1> desc Jadwal_Kuliah;

\begin{tabular}{|c|c|c|c|c|c|c|}
\hline | Field & I & Type & 1 & Null & I Key & I Default \\
\hline I Id_Matkul & 1 & int (8) & 1 & NO & I PRI & I NULL \\
\hline I Mā̃a Kuliah & i & varchar (50) & i & NO & i & I NULL \\
\hline Kelas & i & varchar $(20)$ & i & NO & i & NULL \\
\hline Ruang & $i$ & $\operatorname{varchar}(20)$ & $i$ & No & i & I NULL \\
\hline Status & $i$ & varchar $(20)$ & i & NO & i & I NULL \\
\hline Keterangan & $i$ & $\operatorname{varchar}(40)$ & i & No & i & I NULL \\
\hline Hari Sessi & $i$ & varchar (10) & i & NO & i & I NULL \\
\hline Jam_̄essi & i & time & 1 & No & 1 & | NULL \\
\hline
\end{tabular}

8 rows in set $(0.01 \mathrm{sec})$

mysql> desc Jadwal Session;

\begin{tabular}{|c|c|c|c|c|}
\hline | Field & I Type & I Null & I Key & I Default \\
\hline I Id_Matkul & I int (100) & I NO & | PRI & I NULL \\
\hline I Mata_Kuliah & I varchar (50) & I NO & I & I NULL \\
\hline I Kelas & I varchar (20) & I YES & 1 & I NULL \\
\hline I Ruang & I varchar (20) & I YES & I & I NULL \\
\hline I Status & I varchar (20) & I YES & I & I NULL \\
\hline
\end{tabular}

Gambar 5. Struktur Table Pada Sistem Informasi Jadwal Kuliah

Dapat dilihat pada gambar 5, struktur table yang terdapat pada sistem informasi jadwal terdiri dari beberapa field yang akan menampung ribuan records.
Jadwal_Sessi.

\subsection{FLOW CHART SISTEM}

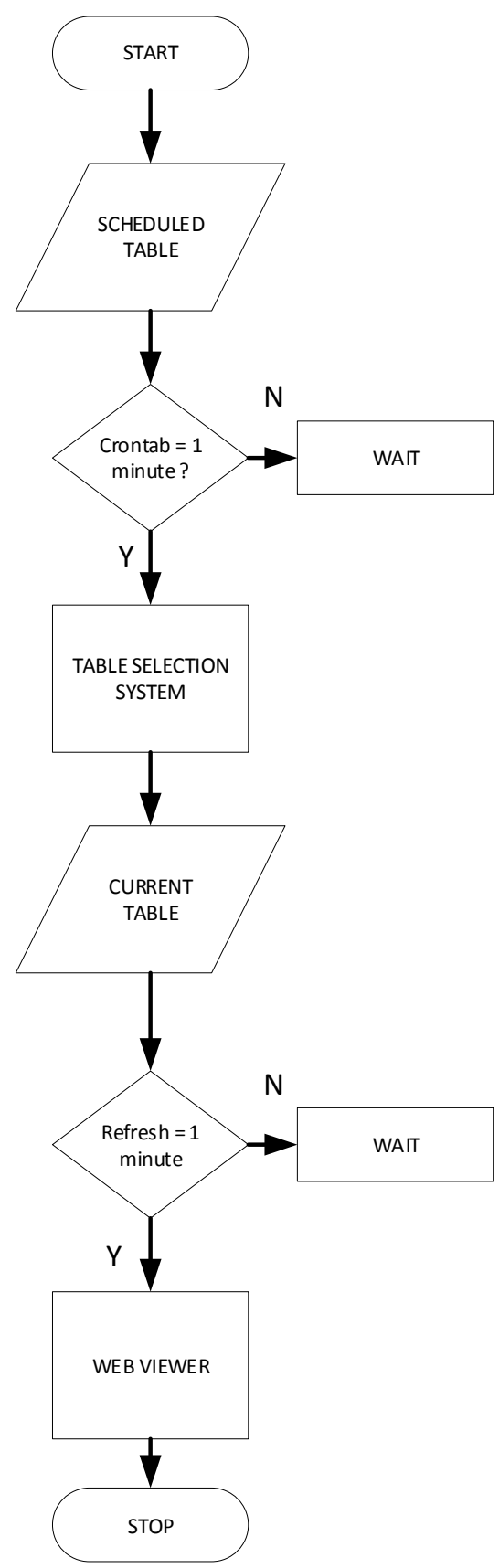

\section{Gambar 5. Flow Chart Sistem Informasi Jadwal Kuliah}

Scheduled table pada gambar 3 adalah data yang telah dimasukkan operator kedalam table Jadwal_Kuliah (lihat gambar 3.) Ketika crontab timeout maka sistem akan meng-ekseskusi skrip php yang men-seleksi data pada table Jadwal_Kuliah berdasarkan hari dan jam dari sistem dan kemudian disesuaikan dengan yang ada pada 
table Jadwal_Kuliah. Data yang terseleksi dimasukkan kedalam ke Current Table pada flowchart (lihat gambar 4) atau kedalam table Jadwal_Session (lihat Gambar 3). Web akan akan menampilkan apa yang terdapat table Jadwal_Session yang hanya berisi data mata kuliah dengan hari dan jam yang sesuai dengan jam sistem.

\section{KESIMPULAN}

Kemampuan Raspberry Pi untuk menopang kegiatan server bisa doandalkan dan tidak mengalami kendala dalam hal operasi-operasi query database, webservice maupun eksekusi php script dengan biaya dan ukuran komputer yang minimal.

Penerapan crontab pada signate board pada sistem infromasi penjadwalan mata kuliah sangat akurat. Interval timer bersifat independen dan tidak mengganggu interval timer yang lain terutama pada sistem interval timer yang dibuat untuk web .

\section{SARAN}

Pembuatan jadwal biasanya menggunakan aplikasi dengan format xlsx, disarankan untuk menambah fitur yang perlu untuk mengkonversikaan data jadwal perkuliahan xlsx ke bentuk yang sesuai dengan struktur table pada database denga format CSV.

Perlu dipertimbangkan juga untuk menerapkan salah satu fitur yang terdapat pada RDBMS MySQL yaitu event scheduler. Fitur ini dapat men-generate interval timer, sehingga ada alternatif selain menggunakan crontab yang hanya terdapat pada sistem operasi linux.

\section{DAFTAR PUSTAKA}

Abrahamsson P, Helmer S, Phaphoom N, $d k k$. Affordable and energy-efficient cloud computing clusters: The bolzano raspberry pi cloud cluster experiment. Proceedings of the Cloud Computing Technology and Science (CloudCom), 2013 IEEE 5th International Conference on, 2013: IEEE, 170-5.

Dictionary CE, 2003. Complete and Unabridged $\odot$ HarperCollins Publishers, 2003. Електронний pecypc. Режим доступу: http://www. thefreedictionary. com/ecology.

Ford CE, Cartwright D, 2018. Digital sign network. In.: Google Patents.

Hussain MA, Langer SG, Kohli M, 2018. Learning HL7 FHIR Using the HAPI FHIR Server and Its Use in Medical Imaging with the SIIM Dataset. Journal of digital imaging 31, 334-40.

Konopásek J, Gojda O, Klimešová D. Spatiotemporal Data Model for Web GIS.

Kraus TM, Manwani VG, Muddana S, 2018. METHOD AND SYSTEM FOR SIMPLIFYING DISTRIBUTED SERVER MANAGEMENT. In.: US Patent App. 15/783,355.
Lakkaraju V, 2010. Database integration and graphical user interface for cyber defense scoring system.

Meis J, Kashima Y, 2017. Signage as a tool for behavioral change: Direct and indirect routes to understanding the meaning of a sign. PloS one 12, $\mathrm{e} 0182975$.

Meloni JC, 2012. Sams teach yourself PHP, MySQL and Apache all in one. Sams Publishing.

O'leary JD, O'leary OF, Cryan JF, Nolan YM, 2018. A low-cost touchscreen operant chamber using a Raspberry $\mathrm{Pi}^{\mathrm{TM}}$. Behavior research methods, 1-8.

Park HW, Bae M, Lee S, Park K, 2018. A study on the sound generation at digital signage using OLED panel. The Journal of the Acoustical Society of America 143, 1838-.

Ritchie DM, Thompson K, 1978. The UNIX timesharing system. Bell System Technical Journal 57, 1905-29.

Russell RF, Gregory Stone A, 2002. A review of servant leadership attributes: Developing a practical model. Leadership \& Organization Development Journal 23, 145-57.

Saito K, Nakamura K, Ueta M, $d k k$., 2015. Utilizing the Cyberforest live sound system with social media to remotely conduct woodland bird censuses in Central Japan. Ambio 44, 572-83.

Ylonen T, Lonvick C, 2005. The secure shell (SSH) protocol architecture. In. 